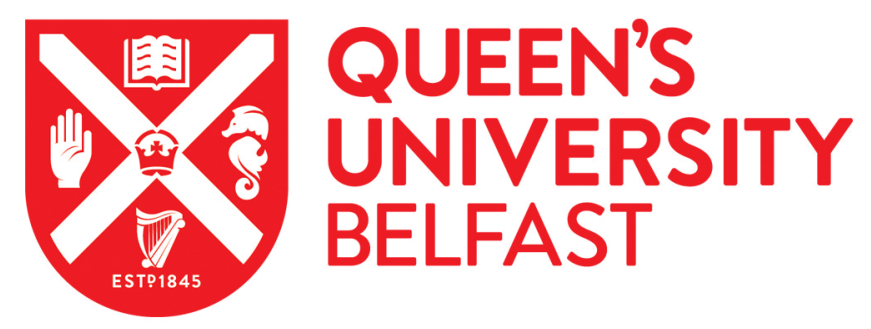

\title{
International variation in oesophageal and gastric cancer survival 2012-2014: differences by histological subtype and stage at diagnosis (an ICBP SURVMARK-2 population-based study)
}

Arnold, M., Morgan, E., Bardot, A., Rutherford, M. J., Ferlay, J., Little, A., Møller, B., Bucher, O., De, P., Woods, R. R., Saint-Jacques, N., Gavin, A. T., Engholm, G., Achiam, M. P., Porter, G., Walsh, P. M., Vernon, S., Kozie, S., Ramanakumar, A. V., ... Soerjomataram, I. (2021). International variation in oesophageal and gastric cancer survival 2012-2014: differences by histological subtype and stage at diagnosis (an ICBP SURVMARK-2 population-based study). Gut. https://doi.org/10.1136/gutjnl-2021-325266

Published in:

Gut

Document Version:

Peer reviewed version

Queen's University Belfast - Research Portal:

Link to publication record in Queen's University Belfast Research Portal

\section{Publisher rights}

Copyright 2021 the authors.

This is an open access Creative Commons Attribution-NonCommercial License (https://creativecommons.org/licenses/by-nc/4.0/), which permits use, distribution and reproduction for non-commercial purposes, provided the author and source are cited.

\section{General rights}

Copyright for the publications made accessible via the Queen's University Belfast Research Portal is retained by the author(s) and / or other copyright owners and it is a condition of accessing these publications that users recognise and abide by the legal requirements associated with these rights.

\section{Take down policy}

The Research Portal is Queen's institutional repository that provides access to Queen's research output. Every effort has been made to ensure that content in the Research Portal does not infringe any person's rights, or applicable UK laws. If you discover content in the Research Portal that you believe breaches copyright or violates any law, please contact openaccess@qub.ac.uk. 
International variation in oesophageal and gastric cancer survival 2012-2014: Differences by histological subtype and stage at diagnosis (an ICBP SURVMARK-2 population-based study)

Melina Arnold $^{1}$, Eileen Morgan ${ }^{1}$, Aude Bardot ${ }^{1}$, Mark J. Rutherford ${ }^{1,2}$, Jacques Ferlay ${ }^{1}$, Alana Little ${ }^{3}$, Bjørn Møller ${ }^{4}$, Oliver Bucher ${ }^{5}$, Prithwish De ${ }^{6}$, Ryan R. Woods ${ }^{7}$, Nathalie Saint-Jacques ${ }^{8}$, Anna Gavin ${ }^{9}$, Gerda Engholm ${ }^{10}$, Michael P. Achiam ${ }^{11}$, Geoff Porter ${ }^{12}$, Paul Walsh ${ }^{13}$, Sally Vernon ${ }^{14}$, Serena Kozie ${ }^{15}$, Agnihotram V. Ramanakumar ${ }^{16}$, Charlotte Lynch $^{17}$, Samantha Harrison ${ }^{17}$, Neil Merrett ${ }^{18}$, Dianne L. $\mathrm{O}^{\prime}$ Connell ${ }^{19}$, Tom Mala ${ }^{20}$, Mark Elwood ${ }^{21}$, John Zalcberg ${ }^{22}$, Dyfed W. Huws ${ }^{23,24}$, David Ransom ${ }^{25}$, Freddie Bray ${ }^{1}$, Isabelle Soerjomataram ${ }^{1}$

1: Cancer Surveillance Branch, International Agency for Research on Cancer (IARC/WHO), 150 Cours Albert Thomas, Lyon, 69372 CEDEX 08, France

2: Biostatistics Research Group, Department of Health Sciences, University of Leicester, University Road, Leicester, LE1 7RH, U.K.

3: Cancer Institute NSW, PO Box 41, Alexandria NSW 1435, Australia

4: Cancer Registry of Norway, Institute of Population-based Cancer Research, P.O. Box 5313

Majorstuen, 0304 Oslo, Norway.

5: Department of Epidemiology and Cancer Registry, Cancercare Manitoba, Winnipeg, MB, Canada

6: Analytics and Informatics, Cancer Care Ontario, 620 University Ave., Toronto, ON M5G 2L7, Canada.

7: BC Cancer, $675 \mathrm{~W}$ 10th Ave, Vancouver, BC V5Z 1L3, Canada

8: Nova Scotia Health Authority Cancer Care Program, Surveillance and Epidemiology Unit, 1276 South Street, Halifax, B3H 2Y9, NS, Canada.

9: Northern Ireland Cancer Registry, Queen's University Belfast, Mulhouse Building, Grosvenor Road, Belfast BT12 6DP, Northern Ireland, United Kingdom.

10: Danish Cancer Society, Strandboulevarden 49, 2100 Copenhagen, Denmark.

11: Danish EsophagoGastric Cancer group, Department of Surgical Gastroenterology, Abdominalcentret, Rigshospitalet, Blegdamsvej 9, 2100 Copenhagen, Denmark

12: Canadian Partnership Against Cancer, 145 King Street West, Suite 900, Toronto, Ontario M5H 1J8, Canada.

13: National Cancer Registry Ireland, Cork Airport Business Park, Kinsale Road, Cork T12 CDF7, Ireland

14: Public Health England, National Cancer Registration and Analysis Service, CB21 5XA, UK

15: Saskatchewan Cancer Agency, Regina SK S4W 0G3, Canada 
16: McGill University Health Centre Research Institute, 1001 Boulevard Décarie, Montreal QC H4A 3J1, Canada

17: International Cancer Benchmarking Partnership (ICBP), Policy \& Information, Cancer Research UK, 22 Redman Place, London, E20 1JQ, UK.

18: Department of Upper Gastrointestinal Surgery, Bankstown-Lidcombe Hospital and School of Medicine, Western Sydney University, Sydney, New South Wales, Australia

19: The Daffodil Centre, The University of Sydney, a joint venture with Cancer Council NSW, Sydney, New South Wales, Australia

20: Department of Gastrointestinal Surgery, Oslo University Hospital, Oslo, Norway

21: School of Population Health, University of Auckland, Auckland, New Zealand

22: School of Public Health and Preventive Medicine, Monash University, Melbourne, Victoria, Australia

23: Welsh Cancer Intelligence and Surveillance Unit, Public Health Wales, Cardiff, Wales, UK

24: Swansea University, Swansea, Wales, UK

25: WA Cancer and Palliative Care Network Policy Unit, Health Networks Branch, Department of Health, Perth, WA, Australia

\section{Corresponding author:}

Melina Arnold, PhD

Cancer Surveillance Branch, International Agency for Research on Cancer (IARC/WHO)

150 Cours Albert Thomas, 69008 Lyon, FRANCE

Phone: +33 (0)4 72738400 ; Fax: +33 (0)4 72738696 ; Email: arnoldm@iarc.fr

Word count: 4,805

Abbreviations: CI - confidence interval; DCO - death certificate only; ECF - epirubicin, cisplatin and 5FU; GERD - gastroesophageal reflux disease; HER2 -- human epidermal growth factor receptor 2; ICBP - International Cancer Benchmarking Partnership; ICD-10 - International Statistical Classification of Diseases and Related Health Problems, 10th Revision; ICD-O-3 - International Classification of Diseases for Oncology, third edition; PET - positron emission tomography; ICSS - International Cancer Survival Standard; OAC - oesophageal adenocarcinoma; OSCC - oesophageal squamous cell carcinoma; SEER Surveillance, Epidemiology and End Results Program; TNM - tumour, node, metastasis; UK - United Kingdom

Keywords: gastric cancer, oesophageal cancer, survival, stage at diagnosis, histology, epidemiology 


\section{Abstract}

Objective: To provide the first international comparison of oesophageal and gastric cancer survival by stage at diagnosis and histological subtype across high-income countries with similar access to healthcare.

Methods: As part of the ICBP SURVMARK-2 project, data from 28,923 oesophageal and 25,946 gastric cancer patients diagnosed during 2012-2014 from 14 cancer registries in seven countries (Australia, Canada, Denmark, Ireland, New Zealand, Norway, and the United Kingdom) were included. One and threeyear age-standardised net survival were estimated by stage at diagnosis, histological subtype (oesophageal adenocarcinoma, OAC; and oesophageal squamous cell carcinoma, OSCC) and country.

Results: Oesophageal cancer survival was highest in Ireland and lowest in Canada at one $(50.3 \%$ versus $41.3 \%$, respectively) and three years $(27.0 \%$ versus $19.2 \%)$ post-diagnosis. Survival from gastric cancer was highest in Australia and lowest in the UK, for both one- (55.2\% versus $44.8 \%$, respectively) and threeyear survival (33.7\% versus 22.3\%). Most oesophageal and gastric cancer patients had regional or distant disease, with proportions ranging between $56 \%$ and $90 \%$ across countries. Stage-specific analyses showed that variation between countries was greatest for localised disease, where survival ranged between $66.6 \%$ in Australia and $83.2 \%$ in the UK for oesophageal cancer and between $75.5 \%$ in Australia and 94.3\% in New Zealand for gastric cancer at one year post-diagnosis. While survival for OAC was generally higher than that for OSCC, disparities across countries were similar for both histological subtypes.

Conclusion: Survival from oesophageal and gastric cancer varies across high-income countries including within stage groups, particularly for localised disease. Disparities can partly be explained by earlier diagnosis resulting in more favourable stage distributions, and distributions of histological subtypes of oesophageal cancer across countries. Yet differences in treatment, but also in cancer registration practice and the use of different staging methods and systems, across countries may have impacted the comparisons. While primary prevention remains key, advancements in early detection research are promising and will likely allow for additional risk stratification and survival improvements in the future. 


\section{Summary Box}

1. What is already known about this subject?

- Despite small improvements in the survival from oesophageal and gastric cancer attributable to important advances in their treatment and management - outcomes from both malignancies remain poor. Yet, differences exist in the prognosis of upper gastrointestinal cancers across countries.

- Stage of disease at diagnosis remains the most important prognostic factor for oesophageal and gastric cancer survival. It however remains unclear to what extent stage at diagnosis and differences in the distribution of histological subtypes explain international survival disparities.

2. What are the new findings?

- Based on high-quality population-based cancer registry data from seven high-income countries, we document important survival differences across populations.

- International variation in survival was most pronounced for localised disease, however representing only a small subset of patients. Most patients continue to be diagnosed at an advanced stage, for which international survival disparities were less distinct.

- While survival from OAC was generally higher than that from OSCC, disparities across countries were similar for both histological subtypes.

3. How might it impact on clinical practice in the foreseeable future?

- This first quantification of international survival differences by stage at diagnosis provides an important evidence-base for clinicians and health policy makers to plan appropriate cancer control.

- The findings suggest international variation in treatment and management strategies in particular for early-stage cancers between countries that warrant further investigation to generate deeper understanding of the drivers of overall survival differences.

- In the absence of efficient and cost-effective population-based screening, primary prevention targeting well-established risk factors such as $H$. pylori infection, tobacco and alcohol consumption, tobacco smoking, body fatness and salt intake, remains key to tackling the overall burden from oesophageal and gastric cancer. 


\section{Introduction}

2 With together more than 1.5 million new cases and over 1.3 million deaths estimated globally in 2020 [1],

3 oesophageal and gastric cancer belong to the group of poor prognosis cancers. Both cancers are often

4 diagnosed at a late stage when treatment options are limited, and outcomes are poor. Although important

5 advances in the treatment and management of oesophago-gastric cancers have led to some improvements

6 in survival over the past years, only about one in five patients survives the disease beyond five years after

7 diagnosis. International disparities in survival from oesophageal and gastric cancer have been described [2]

8 and considerable variation exists across high-income countries with five-year survival estimates ranging

9 from $14.7 \%$ to $23.5 \%$ and from $20.8 \%$ to $32.8 \%$ for oesophageal and gastric cancer patients diagnosed

10 during 2010-2014, respectively.[3]

11 The epidemiology of both cancers has undergone major changes over the past decades. Incidence rates of

12 gastric cancer have continued decreasing in most parts of the world and most of this decline has been

13 attributed to infection with Helicobacter pylori [4], its main causal risk factor. Trends in the incidence of

14 oesophageal cancer are more difficult to unpick, and differ largely between the two main histological

15 subtypes, oesophageal adenocarcinoma (OAC) and squamous cell carcinoma (OSCC). OSCC has been

16 mainly associated with tobacco smoking and heavy alcohol consumption, but also air pollution and

17 unhealthy diet, and represents the most common subtype globally.[5, 6, 7] OAC has been associated with

18 obesity and gastroesophageal reflux disease (GERD) and represents roughly two thirds of oesophageal

19 cancers in high-income countries such as the United Kingdom and the United States [6, 8, 9]

20 The most important prognostic factor determining oesophageal and gastric cancer survival is stage at 21 diagnosis. Yet, as early-stage disease rarely presents any symptoms, late-stage diagnoses remain common, 22 and so treatment options and chances of cure are limited. However, the extent to which differences in stage 23 distributions and survival within stage groups may explain international disparities in survival of these 24 cancers, remains unclear. The International Cancer Benchmarking Partnership (ICBP), an alliance of 25 clinicians, policymakers, researchers, and cancer data experts, was established with the aim to enlighten on 26 the reasons for cancer survival differences between high-income countries with similar health systems.

27 Within the ICBP SURVMARK-2 project, we aim to examine the impact of stage of disease at diagnosis 28 and histological subtype on international survival disparities in oesophageal and gastric cancer. Using 29 population-based data from 14 cancer registries in seven high-income countries (Australia, Canada,

30 Denmark, Ireland, New Zealand, Norway, and the UK), we provide estimates for overall and stage-specific 31 net survival at one and three years post-diagnosis. 


\section{Methods}

\section{Data sources}

34 During the ICBP SURVMARK-2 project, data for patients diagnosed with oesophageal and gastric cancer were collected from 21 population-based cancer registries in seven countries. Data submitted included information on histology, morphology, basis of diagnosis, stage at diagnosis and treatment. Quality checks were conducted on each dataset using a standard data protocol, which is described in more detail elsewhere.[3] This included screening the data for specific anomalies such as instances of negative survival duration, out-of-range dates of diagnosis and/or dates of death, availability of stage at diagnosis information and invalid vital status codes. In the current analyses, we included oesophageal and gastric cancer patients diagnosed during 2012-2014 and followed-up until 31 Dec 2015 from the 14 registries that were able to provide information on stage at diagnosis for at least $50 \%$ of the registered cases : Australia (New South Wales), Canada (Alberta, Manitoba, Newfoundland, Nova Scotia, Prince Edward Island, Saskatchewan), Ireland (2012-2013), Denmark, New Zealand (gastric cancer only), Norway and the UK (England, Wales,

45 Northern Ireland).

Primary malignant oesophageal and gastric tumours (ICD-10: C15 and C16) were included. Histological groups were based on the International Classification of Diseases for Oncology, third edition (ICD-O-3) and defined as OACs: 8140-8141, 8143-8145, 8190-8231, 8260-8263, 8310, 8401, 8480-8490, 8550-8551, 8570-8574 and 8576; OSCCs: 8050-8078 and 8083-8084. We excluded cases diagnosed based on death certificate only (DCO) or at autopsy, below the age of 15 or above 99 years at diagnosis, with inconsistencies in stage information (e.g., incompatibility of basis of diagnosis and stage variables), and second or higher sequenced cancers diagnosed at the same site. Furthermore, we excluded gastrointestinal stromal (8936) and neuroendocrine tumours $(8013,8041-8045,8150-8158,8240-8247,8249,8574$ and 9091) as defined in ICD-O-3 from all analyses as they differ in their aetiology and prognosis from other oesophageal and gastric tumours.[10] Using these criteria, 28,923 oesophageal and 25,964 gastric cancer cases were included in the survival analyses (Table 1).

Each participating cancer registry provided information on pre-treatment pathological and clinical T, N, and M, grouped TNM stage and/or SEER summary stage 2000 (SEER SS2000).[11, 12] For the purpose of stage comparisons across all seven countries, stage information was mapped to one common system by translating individual T, N, M elements to SEER Summary staging (categorized as localised, regional and distant), using a pre-defined mapping algorithm (Supplementary Table 1). While tumours of the proximal (cardia) stomach (C16.0) were staged according to the oesophageal cancer staging scheme, tumours of the 
distal (non-cardia) stomach (C16.1-6, 8-9) were staged using the scheme for gastric cancer, as described in the $7^{\text {th }}$ edition of TNM. [11] Details on the conversion algorithm used are described in Cabasag et al.[13] A summary flowchart of how registry-specific staging information was mapped to SEER staging is available in Supplementary Figure 1.

67 Ethical approval was obtained from each participating registry and from the IARC Ethics Committee 68 (project no. 16-36).

\section{Statistical analyses}

70 We report estimates of net survival with accompanying 95\% confidence intervals (CI), which is the probability of survival for cancer patients in a hypothetical situation where cancer is considered the only possible cause of death. This metric ensures fair survival comparisons across populations in which the chance of dying from other diseases varies. Background mortality in the general population of each jurisdiction was obtained from lifetables of all-cause death probabilities by sex, single year of age and calendar years. Net survival at one and three years post-diagnosis were obtained using Pohar Perme estimators [14] for all oesophageal and gastric cancers as well as for OAC and OSCC, by mapped SEER stage (localised, regional and distant) for all countries and grouped TNM (I, II, III, and IV) for Canada, Denmark, Ireland and the UK, where possible. Sex-specific survival for oesophageal and gastric cancer was also estimated. The cohort approach was used to compute one-year net survival estimates, and the period approach was used to estimate three-year net survival as not all cancer patients had three years of follow-up.[15] Age-standardization was carried out using the International Cancer Survival Standard (ICSS) weights.[16]

83 For cases with missing stage at diagnosis, stage information was imputed using the multiple imputation (mi) command with the following covariates: sex, age, year of diagnosis, survival time, and the NelsonAalen estimator of the cumulative hazard. Age was modelled as a continuous variable and polynomial functions (splines) were used to allow for the non-linear effects of time since diagnosis. Histology (OAC/OSCC/Other) was additionally added to the imputation model for analyses including all oesophageal cancers combined. A total of 30 imputations were performed and results were combined using Rubin's rules to estimate net survival and 95\% confidence interval.[17] results based on original, non-imputed, stage categories in Supplementary tables. 
94 As it is possible that some cancers of the lower oesophagus may have been incorrectly recorded or misclassified as cancers of the gastric cardia (ICD10: C16.0), sensitivity analyses were performed by histological subtype including an additional 8,216 C16.0 cases in the analyses for oesophageal cancer.

97 While we don't present separate results for histological subtypes other than OAC and OSCC - representing

98 between 4 and 9\% of all oesophageal cancer cases across countries-, we evaluated the impact of other

99 histological types on oesophageal cancer survival by comparing estimates including all oesophageal cancer

100 cases with those in the combined group of OAC and OSCC patients. Following a similar reasoning as for 101 oesophageal cancer, we estimated gastric cancer survival after excluding proximal (C16.0) tumours as some 102 of these may have originated from the lower oesophagus and therefore potentially misclassified. Owing to

103 the large proportion of gastric cancer with overlapping or unspecified subsite (ICD-10: C16.8-9), we did 104 not estimate survival for proximal and distal gastric cancers separately.

\section{Patient and Public Involvement}

106 As this work is a retrospective analysis of cancer registry data from the years 2012-2014, patients were not 107 involved in the design and conduct of this research.

\section{Results}

Oesophageal cancer

110 A total of 28,923 cases of oesophageal cancer, including 8,935 cases of OSCC $(30.9 \%)$ and 17,532 cases 111 of OAC (60.6\%) diagnosed during 2012-14 were included in this study (Table 1). OAC was the most 112 common subtype in all countries and accounted for up to two thirds of all oesophageal cancer (in Canada), 113 while OSCC represented between 26.9\% (in Canada) and 44.7\% (in Ireland). Mean age at diagnosis ranged 114 between 67 and 71 years (Table 2), with OAC patients tending to be slightly younger at initial diagnosis 115 (Supplementary Table 2). Information on stage at diagnosis was available for more than $70 \%$ of all patients, 116 and after mapping to summary (SEER or TNM) stage, the proportion with missing stage at diagnosis ranged 117 from $6.4 \%$ in Canada to $29.8 \%$ in Norway.

118 Most oesophageal cancer cases were diagnosed with either regional or distant disease in all countries, 119 however some distinct country-specific patterns were observed (Table 2, Figure 1). While Canada and 120 Denmark had the highest proportion of distant cases $(>50 \%)$, there was a range of $38-44 \%$ in Ireland, 121 Norway, and the UK, and lowest in Australia (31\%). Localised disease was least often diagnosed in 
122 Denmark (9\%) and most often diagnosed in Australia (42\%) and ranged between 12\% and 25\% in the

123 remaining countries. There were similar country-specific patterns in stage distribution by histological

124 subtype, with fewer regional, but slightly more distant disease observed for OAC when compared with

125 OSCC, except for Denmark. The four countries that provided data on TNM stage had similar proportions

126 of stage IV cancers but were dissimilar in the distribution of stage I-III diagnoses.

127 Overall net survival from oesophageal cancer was highest in Ireland and lowest in Canada at one- $(50.3 \%$

128 versus $41.3 \%$, respectively) and three-years (27.0\% versus 19.2\%) post diagnosis (Figure 2, Supplementary

129 Table 3). Variation of stage-specific survival between countries was greatest for localised stage, ranging

130 between $66.6 \%$ in Australia and $82.9 \%$ in Ireland and $83.2 \%$ in the UK at one year and between $43.9 \%$ in

131 Canada and $66.1 \%$ in Ireland at three years post diagnosis. Survival differences across countries for regional

132 and distant stage were smaller, with one-year survival for distant disease ranging between $21.8 \%$ in

133 Australia and 27.2\% in Denmark and three-year survival between 4.4\% in the UK and 7.4\% in Denmark.

134 Similar observations were made for survival from the two main histological subtypes (Figures 2-3,

135 Supplementary Tables 4-5). Survival from OAC was generally better than from OSCC, for all stages

136 combined and for each stage. While one year survival from localised OAC ranged between $73.4 \%$ in

137 Australia and $87.0 \%$ in the UK, this was lower and more variable for patients with localised OSCC (ranging

138 from $53.9 \%$ in Norway to $75.7 \%$ in Ireland). These differences in the subtype-specific survival across stage

139 groups were less pronounced for distant disease and at three years after diagnosis. Analyses by TNM stage

140 confirmed these observations and showed that the high survival observed in Ireland was consistent across

141 all stages and for both histological subtypes. When comparing survival estimates obtained after imputation

142 with those of the original data i.e., including a missing stage category, survival estimates differed slightly,

143 but overall patterns across countries were confirmed. Generally, survival estimates for patients with missing

144 stage were between estimates for regional and distant stage (Supplementary Table 6).

145 Gastric cancer

146 Of 25,946 gastric cancer cases diagnosed in 2012-2014 approximately equal proportions of tumours 147 occurred in the proximal, distal, and other/ unspecified parts of the stomach (Table 1). For tumours with 148 known topography, proximal (cardia) gastric cancer represented the majority in Australia, Denmark, 149 Ireland, and New Zealand (36-52\%) whereas the opposite was observed - distal (non-cardia) tumours being 150 the majority - in Canada, Norway and the UK (37-43\%). About two thirds of all cases occurred in men and 151 the median age at diagnosis ranged between 70 (New Zealand) and 75 years (the UK) (Tables 1-2). The 152 completeness of information on stage at diagnosis varied substantially across countries: while more than $15380 \%$ of gastric cancer cases in Australia, Canada, Denmark and Ireland could be assigned a mapped SEER 
stage, only 54\% of all cases had sufficient information to assign SEER stage in New Zealand (Table 2).

155 Grouped TNM stage was available from four countries, with missing information on stage ranging between

$15612 \%$ (Canada) and 31\% (Ireland and the UK). After imputation of missing stage at diagnosis, most cases

157 were diagnosed with either regional (ranging from $25 \%$ to $42 \%$ of patients in New Zealand and Denmark,

158 respectively) or distant disease (ranging from $38 \%$ to $59 \%$ of patients in Australia and New Zealand,

159 respectively), (Table 2, Figure 1). Localised disease was least often diagnosed in Ireland (10\% of all cases),

160 Denmark and the UK (both 11\%) and most often diagnosed in Australia (33\%) and ranged between 16\%

161 and $20 \%$ in the remaining countries. In the four countries that provided data on grouped TNM, stage

162 distributions were more similar, with approximately half of all gastric cancers having stage IV disease

163 (Table 2, Figure 1).

164 Net survival from gastric cancer was highest in Australia $-55.2 \%$ and $33.7 \%$ at one- and three-years post-

165 diagnosis, respectively, - and lowest in the UK (44.8\% and 22.3\%, respectively) (Figure 2, Supplementary

166 Table 7). Overall, patterns across countries were similar for one- and three-year survival; however, 167 differences became apparent when comparing stage-specific estimated survival. Variation in survival 168 estimates between countries was greatest for patients diagnosed with localised disease, ranging from 94.3\%

169 in New Zealand to $75.5 \%$ in Australia at one year and from $86.5 \%$ in New Zealand to $59.9 \%$ in the UK at 170 three years post diagnosis. Differences in survival across countries for regional and distant stage were 171 smaller, with survival from distant disease highest in Ireland and lowest in the UK at both one- and three172 years post diagnosis, ranging from $26.6 \%$ to $20.7 \%$ at one year and from $8.0 \%$ to $3.8 \%$ at three years post173 diagnosis. Analyses by TNM stage group confirmed these observations, while showing slightly more 174 variation in estimated survival within stage groups, including stage III and IV disease (Figure 3, 175 Supplementary Table 7). When comparing stage-specific survival estimates obtained after multiple 176 imputation with those using the original, non-imputed data, i.e., including missing stage as a separate 177 category, we found that estimates differed only slightly and overall patterns across countries remained the 178 same as those observed using imputed stages (Supplementary Table 8). Cases with missing information on 179 stage at diagnosis had a comparatively poor prognosis, with corresponding estimated survival falling 180 between that for patients with regional and distant stage.

181 In sensitivity analyses, we added cardia gastric cancers to the oesophageal group and showed that while 182 survival estimates changed marginally (increasing in most cases), overall survival patterns across countries 183 remained the same (Supplementary Table 9, Supplementary Figures 2-3). Small differences in survival 184 estimates were also found when comparing all oesophageal cancer patients with the combined group of 185 OSCC and OAC patients (Supplementary Figures 4-5). In secondary analyses for gastric cancer, we 186 additionally examined the impact of proximal gastric cancers by excluding them from the analyses. This 
187 yielded slightly lower estimated net survival at one-year post diagnosis. Excluding proximal tumours only 188 had a marginal impact on estimated three-year survival and on overall patterns across countries

189 (Supplementary Table 10, Supplementary Figures 6-7). Finally, while only small survival differences were 190 observed between male and female gastric cancer patients, females with oesophageal cancer had better 191 survival than their male counterparts (Supplementary Figures 8-9).

\section{Discussion}

193 Survival from oesophageal and gastric cancer continues to vary substantially across high-income countries, 194 including within stage and histological sub-groups. Based on high-quality data from seven countries, we 195 highlighted important international differences in stage distributions across countries with up to $90 \%$ of 196 patients (ranging from $67 \%$ in Australia to $90 \%$ in Ireland for oesophageal and from 58\% in Australia to $19791 \%$ in Denmark for gastric cancers) presenting with either regional or distant spread of the tumour at the 198 time of diagnosis. We found that while survival for patients with distant disease varied little across 199 countries, differences in survival were most pronounced for localised disease, where survival ranged widely 200 for both cancers. High proportions of late-stage disease across all jurisdictions suggests greater efforts in 201 earlier diagnosis and staging work-up of upper gastrointestinal cancer may be warranted internationally.

202 To our knowledge we are the first to describe international survival differences by stage at diagnosis for 203 oesophageal and gastric cancer patients. Recent studies from the US [18, 19] and Norway [20] which 204 presented survival at five years post-diagnosis, noted overall improvements in survival for all stages in the 205 absence of notable changes in stage distributions over time. As many as 51\% of oesophageal cancer cases 206 and 59\% of all gastric cancer cases were diagnosed with distant disease. Therefore, there is an urgent need 207 for tools enabling early diagnosis including novel biomarkers and less invasive screening methods for 208 oesophageal cancer, such as inflatable balloons and sponges.[21, 22] The more recent trial of the 209 'cytosponge' has developed a less invasive, and rapid screening test for oesophageal cancer, specifically 210 OAC.[23] The use of this screening method varies internationally, and does not align with the time period 211 studied, but our study highlights the need to consider the adoption and implementation of approaches like 212 the 'cytosponge', particularly in high-incidence populations with high proportions of late stage 213 presentations. For gastric cancer, at present, population-based screening programs have only proven cost214 efficient in high-risk populations such as Japan or Republic of? Korea where incidence rates of gastric 215 cancer are among the highest in the world.[24, 25] The larger proportions of patients with localised disease 216 in Australia, Canada and Norway could be due to higher awareness of patients with precursors of OAC 217 (such as gastro-oesophageal reflux disease or Barrett's oesophagus), which could equally originate or be 
218 misclassified as cancers of the proximal stomach.[26, 27] OAC today represents the most common type of

219 oesophageal cancer in all included countries, pointing towards an increasing incidence of cancers of the

220 oesophago-gastric junction.[28]

221 The survival advantage observed for OAC compared with OSCC, particularly for those with localised or 222 regional disease, could partly be due to differences in the aetiology of these two groups. Patients with OSCC 223 may have additional comorbidities related to smoking (a major risk factor for this sub-type) which could 224 play a part in their treatment options and poorer survival.[29] The higher survival observed for Ireland could 225 potentially be explained by lower proportions of distant disease (40\% of cases) and higher survival for 226 localised and regional disease compared to other countries due to improvements in the treatment protocols 227 including neo-adjuvant therapy for resectable, localised cases. Survival is higher for patients with locally 228 advanced disease when chemoradiotherapy followed by surgery is administered compared with surgery 229 alone, for both OAC and OSCC.[30] It should however, be noted that this study covered a period where 230 neoadjuvant chemoradiotherapy had not yet been fully adopted in all jurisdictions for lower oesophageal 231 adenocarcinoma, as it preceded publication of the CROSS study in 2015.[31] Furthermore, endoscopic 232 Barrett's oesophagus screening and surveillance in high-risk individuals could have contributed to earlier 233 detection of $\mathrm{OAC}$, and, in combination with minimally invasive techniques in the management of localized 234 OAC, to better outcomes when compared with OSCC.[32]

235 Higher survival observed within stage groups of gastric cancer, in particular those diagnosed with early and 236 regional disease, is potentially attributable to varying treatment and management of patients across 237 countries as well as possible differences in the prevalence of comorbidities, e.g., obesity. Since the 238 publication of the MAGIC trial in 2006, reporting survival benefits for patients receiving perioperative 239 chemotherapy consisting of epirubicin, cisplatin and 5-FU (ECF), (neo)adjuvant chemotherapy became an 240 important element in the treatment of stage I-III gastric cancer.[33] To-date, first-line treatment for gastric 241 cancer includes surgery for early-stage disease and multimodal approaches for locally advanced and 242 metastatic disease. These include surgery followed by chemoradiation, or chemotherapy before and after 243 surgery for locally advanced disease and chemotherapy, immunotherapy (in particular anti-HER2244 therapies), or chemoradiation and supportive care for patients with metastatic disease. Treatment 245 approaches might differ across countries, leading to discrepancies in surgical techniques, different types of 246 adjuvant therapy and treatment sequence.[34] This is particularly evident in the elderly, when gastric cancer 247 is most common and often coupled with comorbidity and frailty, where evidence for optimal treatment 248 strategies is limited. According to previous evidence, treatment differences exist across North European 249 countries for patients with stages II and III resectable gastric cancer aged 70 years or older.[35] 
Moreover, centralisation of treatment for oesophago-gastric cancer might contribute to the observed survival differences across countries. Several European countries, including the UK, Ireland, the

252 Netherlands, Norway, Denmark, and New South Wales in Australia have implemented centralisation of 253 oesophago-gastric cancer treatment, which has led to improved survival and reduced post-operative 254 mortality in some settings. [36, 37, 38, 39] This could partly explain the consistently high survival within 255 all stage groups in Ireland, where effects of centralisation of stomach cancer services (started in 2007) were 256 found to be strongest for surgical treatment and higher survival was observed for patients treated in one of 257 the eight specialist centres, compared with other public hospitals.[39] It may still be too early to observe 258 the full effects of these recent changes in organisation of cancer services on outcomes in other countries, 259 but initial evaluations are promising. It should also be noted that this study period covered a transition 260 period in New South Wales where centralisation was in the process of implementation. Lower post261 operative mortality rates observed in high-volume hospitals in England may furthermore support the 262 centralisation of oesophageal and gastric cancer surgical services and may partly explain survival 263 differences across countries after resection.[40] More robust in-depth studies exploring the impact of 264 centralisation of services and cancer outcomes internationally are warranted to further understand this 265 relationship.

266 In addition to the factors outlined above, several other factors may explain better or worse survival in a 267 population or sub-population. The introduction of screening programs and prophylactic gastrectomies 268 targeting high-risk individuals may have led to an increased identification at early stage and therefore better 269 survival e.g., in New Zealand. More biological factors have also been reported, for example, germline $270 \mathrm{CDH} 1$ mutations have been found to contribute to the high frequency of early-onset diffuse gastric cancer 271 cases in the Māori population of New Zealand, who carry a disproportionate burden from this cancer.[41, 272 42] Finally, previous studies have documented survival advantages in women when compared with men, 273 pointing towards sex as an independent prognostic factor.[43, 44] We confirmed this observation for 274 oesophageal cancer, but only marginal differences in gastric cancer survival by sex.

275 The data used for this study were provided by high-quality cancer registries from countries with similar 276 access to healthcare. We ensured the highest possible data quality and comparability at all stages of data 277 collection and harmonization using a predefined protocol. All results were validated and interpreted with 278 the input of local experts, including registry experts, epidemiologists, and clinicians from each country. 279 Despite these precautions, a few limitations should be noted. First, notwithstanding marked improvements 280 over the past decade, information on stage at diagnosis for both oesophageal and gastric cancer is still often 281 missing or incomplete in cancer registry records. Out of 21 cancer registries participating in the ICBP282 SURVMARK2 study, only 14 were able to provide sufficient data on stage at diagnosis. Moreover, patients 
with missing stage information tended to be older at diagnosis (Table 2) and therefore less likely to have undergone invasive diagnostic procedures and radical treatment. However, cases with missing stage did not exclusively represent those with the worst outcomes, given that their survival was often closer to that for patients diagnosed with regional rather than distant disease. By imputing missing stage at diagnosis separately for each country and by incorporating important measures of survival time, we included the main determinants of stage to inform stage distributions and to mitigate differential missingness patterns across countries. We showed that both approaches (with and without imputation) led to very similar estimates of stage-specific survival.

Second, when merging information from different staging systems, misclassification may occur, potentially confounding stage distributions and survival estimates. We tried to mitigate this by carefully comparing the different classification systems and involving staging experts and clinicians in the conversion to one common system. While stage information was not converted for the Australian data as it was provided in the SEER format, the stage distribution for New South Wales differed markedly from other countries, with a very large proportion of cases diagnosed with localised (42\% for oesophageal and 33\% for gastric cancers) and relatively small proportions with regional (27\% and $29 \%$, respectively) and distant disease (31\% and $38 \%$ respectively). Coupled with the relatively low survival from localised oesophageal cancer in New South Wales, this group likely contains a mixture of localised and regional disease, which we were not able to examine further as there was no additional information on stage or treatment. Similar observations were made for Norway. This clearly illustrates the limits of stage-specific analyses and the comparability of results in this study, which should be interpreted with caution, especially for New South Wales. We are also aware of varying staging modalities across jurisdictions. The access to more specialised staging modalities such as positron emission tomography (PET) scans, are variable between and even within jurisdictions and may influence the patient's final stage staging.[45] While, for the purpose of comparison, we used the SEER system to compare stage-specific survival estimates across countries, it should be noted that TNM remains the preferred staging classification, as it reflects patients' groupings in clinical settings. The utilisation of a recently developed and simplified set of TNM rules, called essential TNM, might

Third, the prognostic staging of oesophageal and gastric cancer should ideally take into account both the

313 topographic location and the histological type of the tumour. Proximal gastric cancers as well as cancers of 314 the diffuse Lauren type histology [47] have a worse prognosis when compared with distal (non-cardia) and 315 intestinal types.[20,48] Given the large proportion of gastric cancers with unknown anatomic subsite, 316 representing up to one third of all cases, we were unable to analyse survival by subsite. Furthermore, since 
317 the $7^{\text {th }}$ edition of the TNM classification of malignant tumours[11], cancers of the oesophago-gastric

318 junction (C16.0) that extend into the oesophagus are staged using the oesophageal scheme as they are

319 considered the same clinical entity. As junctional cancers are sometimes difficult to classify and registration

320 practices might differ across countries, in sensitivity analyses we estimated survival for cancers of the

321 oesophagus including cancers of the oesophago-gastric junction and gastric cancer excluding these

322 junctional cancers. While survival estimates changed slightly, patterns and differences across countries

323 remained, suggesting that the differential misclassification of junctional cancers can only marginally add

324 to the explanation of survival disparities between countries. Fourth, while treatment data were part of the

325 data request of this project, only few registries were able to provide this information, often only for a small

326 subset of patients. We were therefore unable to evaluate the impact of treatment on international survival

327 differences in this study. Finally, while all efforts were made to reach the highest possible degree of data

328 comparability, other differences in registration practice may have affected our results. These limitations

329 should be considered when interpreting the results, including uncontrolled confounding.

331 In conclusion, disparities in oesophageal and gastric cancer survival across high-income countries were

332 observed, most notably for localised disease. This suggests international variation in treatment and

333 management strategies between countries and warrants further investigation of these procedures and

334 protocols to generate deeper understanding of the drivers of overall survival differences. Most cases of both

335 malignancies continue to be diagnosed at an advanced stage across all countries suggesting greater efforts

336 are universally required to improve early diagnosis. In the absence of efficient and cost-effective

337 population-based screening, primary prevention targeting well-established risk factors such as $H$. pylori

338 infection, tobacco and alcohol consumption, tobacco smoking, body fatness and salt intake, remains key to

339 tackling the overall burden from oesophageal and gastric cancer. Considering important limitations related

340 to the comparability of staging systems and methods, stage-specific comparisons should be interpreted with

341 caution. Evidently, the improved collection and standardisation of staging data, and the accrual of additional

342 variables such as treatment and co-morbidities are critical steps in developing a complete understanding of

343 the underlying mechanisms that explain international differences in cancer survival.

\section{Acknowledgements}

345 The authors would like to thank Lucie Hooper, Samantha Harrison, Charles Norell, Shanta Keshwala and

346 Charlotte Lynch of Cancer Research UK for managing the programme. The ICBP SurvMark-2 Local Leads

347 for their contributions to the study protocol and advice to help understand the data. The ICBP Clinical

348 Committees for their interpretation of the results and the ICBP SurvMark-2 Academic Reference Group for 
349 providing independent peer review and advice for the study protocol and analysis plan development.

350 Finally, we are thankful to the ICBP Programme Board for their oversight and direction.

351 Where authors are identified as personnel of the International Agency for Research on Cancer / World

352 Health Organization, the authors alone are responsible for the views expressed in this article and they do

353 not necessarily represent the decisions, policy or views of the International Agency for Research on

354 Cancer/World Health Organization.

356 Funding: The ICBP is funded by the Canadian Partnership Against Cancer; Cancer Council Victoria; 357 Cancer Institute New South Wales; Cancer Research UK; Danish Cancer Society; National Cancer Registry 358 Ireland; The Cancer Society of New Zealand; NHS England; Norwegian Cancer Society; Public Health 359 Agency Northern Ireland, on behalf of the Northern Ireland Cancer Registry; The Scottish Government; 360 Western Australia Department of Health; Wales Cancer Network.

361 Competing interests: All authors declare no relevant competing interests.

\section{Contributorship statement}

363 Study concept and design: MA, IS. Data analysis: MA, AB, MJR. Data collection and interpretation: EM, 364 JF, AL, BM, OB, PD, RRW, NSJ, AG, GE, MPA, GP, PW, SV, SK, AVR, CL, SH, NM, DOC, TM, ME, 365 JZ, DWH, DR, FB. Drafting the manuscript: MA, EM, IS. Critical revision of the manuscript for 366 important intellectual content: all authors. 


\section{References}

3671 Sung H, Ferlay J, Siegel RL, Laversanne M, Soerjomataram I, Jemal A, et al. Global cancer

368

369

370

371

372

373

374

375

376

377

378

379

380

381

382

383

384

385

386

387

388

389

390

391

392

393

394

395

396

397

398

399

400

401

402

403

404

405

406

407

408

409

410

411

412 statistics 2020: GLOBOCAN estimates of incidence and mortality worldwide for 36 cancers in 185 countries. CA Cancer J Clin 2021.

2 Allemani C, Matsuda T, Di Carlo V, Harewood R, Matz M, Niksic M, et al. Global surveillance of trends in cancer survival 2000-14 (CONCORD-3): analysis of individual records for 37513025 patients diagnosed with one of 18 cancers from 322 population-based registries in 71 countries. Lancet 2018;391:1023-75.

3 Arnold M, Rutherford MJ, Bardot A, Ferlay J, Andersson TM, Myklebust TA, et al. Progress in cancer survival, mortality, and incidence in seven high-income countries 1995-2014 (ICBP

SURVMARK-2): a population-based study. Lancet Oncol 2019;20:1493-505.

4 de Martel C, Georges D, Bray F, Ferlay J, Clifford GM. Global burden of cancer attributable to infections in 2018: a worldwide incidence analysis. Lancet Glob Health 2019.

5 Abnet CC, Arnold M, Wei WQ. Epidemiology of Esophageal Squamous Cell Carcinoma. Gastroenterology 2018;154:360-73.

6 Arnold M, Soerjomataram I, Ferlay J, Forman D. Global incidence of oesophageal cancer by histological subtype in 2012. Gut 2015;64:381-7.

7 Sheikh M, Poustchi H, Pourshams A, Etemadi A, Islami F, Khoshnia M, et al. Individual and Combined Effects of Environmental Risk Factors for Esophageal Cancer Based on Results From the Golestan Cohort Study. Gastroenterology 2019;156:1416-27.

8 McColl KEL. What is causing the rising incidence of esophageal adenocarcinoma in the West and will it also happen in the East? J Gastroenterol 2019;54:669-73.

9 Thrift AP. The epidemic of oesophageal carcinoma: Where are we now? Cancer Epidemiol 2016;41:88-95.

10 Genus TSE, Bouvier C, Wong KF, Srirajaskanthan R, Rous BA, Talbot DC, et al. Impact of neuroendocrine morphology on cancer outcomes and stage at diagnosis: a UK nationwide cohort study 2013-2015. Br J Cancer 2019;121:966-72.

11 Sobin LH, Gospodarowicz MK, Wittekind C, International Union against Cancer. TNM classification of malignant tumours. Chichester, West Sussex, UK ; Hoboken, NJ: Wiley-Blackwell, 2010.

12 SEER Summary Staging Manual - 2000: Codes and Coding Instructions. In: Young JLJ, Roffers SD, Ries LA, Fritz AG, Hurlbut AA, eds. Bethesda, MD: National Cancer Institute, 2001.

13 Cabasag CJ, Arnold M, Pineros M, Morgan E, Brierley J, Hofferkamp J, et al. Population-based cancer staging for oesophageal, gastric, and pancreatic cancer 2012-2014: International Cancer Benchmarking Partnership SurvMark-2. Int J Cancer 2021;149:1239-46.

14 Perme MP, Stare J, Esteve J. On estimation in relative survival. Biometrics 2012;68:113-20.

15 Brenner H, Hakulinen T. Period versus cohort modeling of up-to-date cancer survival. Int J Cancer 2008;122:898-904.

16 Corazziari I, Quinn M, Capocaccia R. Standard cancer patient population for age standardising survival ratios. Eur J Cancer 2004;40:2307-16.

17 Campion WM. Multiple Imputation for Nonresponse in Surveys - Rubin,Db. J Marketing Res 1989;26:485-6.

18 Jim MA, Pinheiro PS, Carreira H, Espey DK, Wiggins CL, Weir HK. Stomach cancer survival in the United States by race and stage (2001-2009): Findings from the CONCORD-2 study. Cancer 2017;123 Suppl 24:4994-5013.

19 He H, Chen N, Hou Y, Wang Z, Zhang Y, Zhang G, et al. Trends in the incidence and survival of patients with esophageal cancer: A SEER database analysis. Thorac Cancer 2020;11:1121-8. 
20 Bringeland EA, Wasmuth HH, Mjones P, Myklebust TA, Gronbech JE. A population-based study on incidence rates, Lauren distribution, stage distribution, treatment, and long-term outcomes for gastric adenocarcinoma in Central Norway 2001-2011. Acta Oncol 2017;56:39-45.

41822 Offman J, Muldrew B, O’Donovan M, Debiram-Beecham I, Pesola F, Kaimi I, et al. Barrett's oESophagus trial 3 (BEST3): study protocol for a randomised controlled trial comparing the CytospongeTFF3 test with usual care to facilitate the diagnosis of oesophageal pre-cancer in primary care patients with chronic acid reflux. BMC Cancer 2018;18:784.

23 Fitzgerald R DPM, O'Donovan M et al. Cytosponge-trefoil factor 3 versus usual care to identify Barrett's oesophagus in a primary care setting: a multicentre, pragmatic, randomised controlled trial. The Lancet Oncology 2020.

24 Hamashima C, Systematic Review G, Guideline Development Group for Gastric Cancer Screening G. Update version of the Japanese Guidelines for Gastric Cancer Screening. Jpn J Clin Oncol 2018;48:673-83.

25 Jun JK, Choi KS, Lee HY, Suh M, Park B, Song SH, et al. Effectiveness of the Korean National Cancer Screening Program in Reducing Gastric Cancer Mortality. Gastroenterology 2017;152:1319-28 e7.

43126 McColl KE, Going JJ. Aetiology and classification of adenocarcinoma of the gastro-oesophageal 432 junction/cardia. Gut 2010;59:282-4.

43327 El-Serag HB, Naik AD, Duan Z, Shakhatreh M, Helm A, Pathak A, et al. Surveillance endoscopy

434 is associated with improved outcomes of oesophageal adenocarcinoma detected in patients with Barrett's 435 oesophagus. Gut 2016;65:1252-60.

43628 Morgan E, Soerjomataram I, Gavin AT, Rutherford MJ, Gatenby P, Bardot A, et al. International trends in oesophageal cancer survival by histological subtype between 1995 and 2014. Gut 2021;70:23442.

29 McMenamin UC, McCain S, Kunzmann AT. Do smoking and alcohol behaviours influence GI cancer survival? Best Pract Res Clin Gastroenterol 2017;31:569-77.

30 Shapiro J, van Lanschot JJB, Hulshof M, van Hagen P, van Berge Henegouwen MI, Wijnhoven BPL, et al. Neoadjuvant chemoradiotherapy plus surgery versus surgery alone for oesophageal or junctional cancer (CROSS): long-term results of a randomised controlled trial. Lancet Oncol 2015;16:1090-8.

31 Shapiro J vLJ, Hulshof M, van Hagen P, van Berge Henegouwen MI, Wijnhoven BPL, et al. Neoadjuvant chemoradiotherapy plus surgery versus surgery alone for oesophageal or junctional cancer (CROSS): long-term results of a randomised controlled trial. Lancet Oncology 2015.

32 Sharma P, Sidorenko EI. Are screening and surveillance for Barrett's oesophagus really worthwhile? Gut 2005;54 Suppl 1:i27-32.

33 Cunningham D, Allum WH, Stenning SP, Thompson JN, Van de Velde CJ, Nicolson M, et al. Perioperative chemotherapy versus surgery alone for resectable gastroesophageal cancer. N Engl J Med 2006;355:11-20.

34 Kilic L, Ordu C, Yildiz I, Sen F, Keskin S, Ciftci R, et al. Current adjuvant treatment modalities for gastric cancer: From history to the future. World J Gastrointest Oncol 2016;8:439-49.

35 Claassen YHM, Dikken JL, Hartgrink HH, de Steur WO, Slingerland M, Verhoeven RHA, et al. North European comparison of treatment strategy and survival in older patients with resectable gastric cancer: A EURECCA upper gastrointestinal group analysis. Eur J Surg Oncol 2018;44:1982-9.

36 van de Poll-Franse LV, Lemmens VE, Roukema JA, Coebergh JW, Nieuwenhuijzen GA. Impact of concentration of oesophageal and gastric cardia cancer surgery on long-term population-based survival. 460 Br J Surg 2011;98:956-63.

46137 van Putten M, Nelen SD, Lemmens V, Stoot J, Hartgrink HH, Gisbertz SS, et al. Overall survival 462 before and after centralization of gastric cancer surgery in the Netherlands. Br J Surg 2018;105:1807-15. 
38 Jensen LS, Nielsen H, Mortensen PB, Pilegaard HK, Johnsen SP. Enforcing centralization for gastric cancer in Denmark. Eur J Surg Oncol 2010;36 Suppl 1:S50-4.

39 Cancer care and survival in relation to centralisation of Irish cancer services: an analysis of National Cancer Registry data 1994-2015. Cork, Ireland: National Cancer Registry (NCRI), 2019.

$46740 \quad$ Coupland VH, Lagergren J, Luchtenborg M, Jack RH, Allum W, Holmberg L, et al. Hospital

468 volume, proportion resected and mortality from oesophageal and gastric cancer: a population-based study

469 in England, 2004-2008. Gut 2013;62:961-6.

$47041 \quad$ Hakkaart C, Ellison-Loschmann L, Day R, Sporle A, Koea J, Harawira P, et al. Germline CDH1

471 mutations are a significant contributor to the high frequency of early-onset diffuse gastric cancer cases in

472 New Zealand Maori. Fam Cancer 2019;18:83-90.

$47342 \quad$ Arnold M, Moore SP, Hassler S, Ellison-Loschmann L, Forman D, Bray F. The burden of

474 stomach cancer in indigenous populations: a systematic review and global assessment. Gut 2014;63:64-

47571.

$47643 \quad$ Bohanes P, Yang D, Chhibar RS, Labonte MJ, Winder T, Ning Y, et al. Influence of sex on the

477 survival of patients with esophageal cancer. J Clin Oncol 2012;30:2265-72.

47844 Haupt S, Caramia F, Klein SL, Rubin JB, Haupt Y. Sex disparities matter in cancer development 479 and therapy. Nat Rev Cancer 2021;21:393-407.

$48045 \quad$ Lynch C, Reguilon I, Langer DL, Lane D, De P, Wong WL, et al. A comparative analysis:

481 international variation in PET-CT service provision in oncology-an International Cancer Benchmarking

482 Partnership study. Int J Qual Health Care 2021;33.

48346 Pineros M, Parkin DM, Ward K, Chokunonga E, Ervik M, Farrugia H, et al. Essential TNM: a

484 registry tool to reduce gaps in cancer staging information. Lancet Oncol 2019;20:e103-e11.

48547 Lauren P. The Two Histological Main Types of Gastric Carcinoma: Diffuse and So-Called

486 Intestinal-Type Carcinoma. An Attempt at a Histo-Clinical Classification. Acta Pathol Microbiol Scand $487 \quad 1965 ; 64: 31-49$.

48848 Anderson LA, Tavilla A, Brenner H, Luttmann S, Navarro C, Gavin AT, et al. Survival for 489 oesophageal, stomach and small intestine cancers in Europe 1999-2007: Results from EUROCARE-5.

490 Eur J Cancer 2015;51:2144-57. 
Table 1. Characteristics of patients with oesophageal and gastric cancer diagnosed during 2012-2014

\begin{tabular}{|c|c|c|c|c|c|c|c|c|}
\hline & \multicolumn{8}{|c|}{ Oesophageal cancer } \\
\hline & Australia $^{\circ}$ & Canada $^{\dagger}$ & Denmark & Ireland ${ }^{\llbracket}$ & New Zealand & Norway & $\begin{array}{c}\text { United } \\
\text { Kingdom }\end{array}$ & Total \\
\hline $\begin{array}{l}\text { Number of patients diagnosed } \\
\text { during 2012-2014 }\end{array}$ & 1,424 & 1,328 & 1,582 & 769 & & 797 & 24,037 & 29,937 \\
\hline \multicolumn{9}{|l|}{ Total exclusions } \\
\hline $\begin{array}{l}\text { Diagnosed based on death } \\
\text { certificate only (DCO) or autopsy }\end{array}$ & $34(2.4 \%)$ & $9(0.7 \%)$ & $2(0.1 \%)$ & $5(0.7 \%)$ & & $13(1.6 \%)$ & $309(1.3 \%)$ & $372(1.2 \%)$ \\
\hline Quality control $^{\Delta}$ & $4(0.3 \%)$ & - & - & - & & - & - & $4(0.0 \%)$ \\
\hline Age $<15$ or $>99$ years & $1(0.1 \%)$ & $1(0.1 \%)$ & - & $1(0.1 \%)$ & & - & $17(0.1 \%)$ & $20(0.1 \%)$ \\
\hline $\begin{array}{l}\text { Second or higher order cancers at } \\
\text { the same site }\end{array}$ & $2(0.1 \%)$ & - & $3(0.2 \%)$ & $3(0.4 \%)$ & & $1(0.1 \%)$ & $15(0.1 \%)$ & $24(0.1 \%)$ \\
\hline $\begin{array}{l}\text { Cases with inconsistencies in } \\
\text { stage information* }\end{array}$ & - & - & $5(0.3 \%)$ & $2(0.3 \%)$ & & - & $50(0.2 \%)$ & $57(0.2 \%)$ \\
\hline $\mathrm{GIST}^{\overline{\mathbf{T}}}$ & - & - & $4(0.3 \%)$ & $1(0.1 \%)$ & & $3(0.4 \%)$ & $10(0.0 \%)$ & $18(0.1 \%)$ \\
\hline Neuroendocrine tumours ${ }^{\S}$ & $18(1.3 \%)$ & $28(2.1 \%)$ & $46(2.9 \%)$ & $16(2.1 \%)$ & & $19(2.4 \%)$ & $392(1.6 \%)$ & $519(1.7 \%)$ \\
\hline $\begin{array}{l}\text { Total cases eligible for survival } \\
\text { analysis }\end{array}$ & $\begin{array}{c}1,365 \\
(95.9 \%)\end{array}$ & $1,290(97.1 \%)$ & $\begin{array}{c}1,522 \\
(96.2 \%)\end{array}$ & $741(96.4 \%)$ & & $761(95.5 \%)$ & $\begin{array}{c}23,244 \\
(96.7 \%)\end{array}$ & $\begin{array}{c}28,923 \\
(96.6 \%)\end{array}$ \\
\hline$\%$ Males & $68.1 \%$ & $78.5 \%$ & $73.7 \%$ & $65.3 \%$ & & $75.3 \%$ & $67.9 \%$ & $68.8 \%$ \\
\hline \multicolumn{9}{|l|}{ Histological subtype } \\
\hline Squamous Cell Carcinoma & $521(38.2 \%)$ & $347(26.9 \%)$ & $643(42.2 \%)$ & $331(44.7 \%)$ & & $248(32.6 \%)$ & $\begin{array}{c}6,845 \\
(29.4 \%)\end{array}$ & $\begin{array}{c}8,935 \\
(30.9 \%)\end{array}$ \\
\hline Adenocarcinoma & $745(54.6 \%)$ & $847(65.7 \%)$ & $816(53.6 \%)$ & $359(48.4 \%)$ & & $446(58.6 \%)$ & $\begin{array}{c}14,319 \\
(61.6 \%)\end{array}$ & $\begin{array}{l}17,532 \\
(60.6 \%)\end{array}$ \\
\hline \multirow[t]{3}{*}{ Other } & $99(7.3 \%)$ & $96(7.4 \%)$ & $63(4.1 \%)$ & $51(6.9 \%)$ & & $67(8.8 \%)$ & $2,080(8.9 \%)$ & $2,456(8.5 \%)$ \\
\hline & \multicolumn{8}{|c|}{ Gastric cancer } \\
\hline & Australia $^{\circ}$ & Canada $^{\dagger}$ & Denmark & Ireland & New Zealand & Norway & $\begin{array}{c}\text { United } \\
\text { Kingdom }^{\ddagger} \\
\end{array}$ & Total \\
\hline $\begin{array}{l}\text { Number of patients diagnosed } \\
\text { during 2012-2014 }\end{array}$ & 2,078 & 1,929 & 1,636 & 1,096 & 1,145 & 1,416 & 18,933 & 28,233 \\
\hline \multicolumn{9}{|l|}{ Total exclusions } \\
\hline $\begin{array}{l}\text { Diagnosed based on death } \\
\text { certificate only (DCO) or autopsy }\end{array}$ & $36(1.7 \%)$ & $12(0.6 \%)$ & $5(0.3 \%)$ & $9(0.8 \%)$ & $7(0.6 \%)$ & $23(1.6 \%)$ & $358(1.9 \%)$ & $450(1.6 \%)$ \\
\hline Quality control $^{\Delta}$ & $2(0.1 \%)$ & $3(0.2 \%)$ & - & - & - & - & - & $5(0.0 \%)$ \\
\hline Age $<15$ or $>99$ years & $1(0.0 \%)$ & $1(0.1 \%)$ & - & - & $1(0.1 \%)$ & $2(0.1 \%)$ & $14(0.1 \%)$ & $19(0.1 \%)$ \\
\hline $\begin{array}{l}\text { Second or higher order cancers at } \\
\text { the same site }\end{array}$ & $6(0.3 \%)$ & $7(0.4 \%)$ & $2(0.1 \%)$ & $4(0.4 \%)$ & - & $3(0.2 \%)$ & $47(0.2 \%)$ & $69(0.2 \%)$ \\
\hline $\begin{array}{l}\text { Cases with inconsistencies in } \\
\text { stage information* }\end{array}$ & - & $1(0.1 \%)$ & $7(0.4 \%)$ & $3(0.3 \%)$ & - & $1(0.1 \%)$ & $41(0.2 \%)$ & $53(0.2 \%)$ \\
\hline $\mathrm{GIST}^{\bar{\top}}$ & $61(2.9 \%)$ & $57(3.0 \%)$ & $107(6.5 \%)$ & $18(1.6 \%)$ & $30(2.6 \%)$ & $47(3.3 \%)$ & $387(2.0 \%)$ & $707(2.5 \%)$ \\
\hline Neuroendocrine tumours ${ }^{\S}$ & $82(3.9 \%)$ & $111(5.8 \%)$ & $43(2.6 \%)$ & $55(5.0 \%)$ & $29(2.5 \%)$ & $53(3.7 \%)$ & $593(3.1 \%)$ & $966(3.4 \%)$ \\
\hline $\begin{array}{l}\text { Total cases eligible for survival } \\
\text { analysis }\end{array}$ & $\begin{array}{c}1,890 \\
(91.0 \%)\end{array}$ & $1,737(90.0 \%)$ & $\begin{array}{c}1,472 \\
(90.0 \%)\end{array}$ & $\begin{array}{c}1,007 \\
(91.9 \%)\end{array}$ & $\begin{array}{c}1,078 \\
(94.1 \%)\end{array}$ & $1,287(90.9 \%)$ & $\begin{array}{c}17,493 \\
(92.4 \%)\end{array}$ & $\begin{array}{c}25,964 \\
(92.0 \%)\end{array}$ \\
\hline$\%$ Males & $66.8 \%$ & $67.4 \%$ & $68.0 \%$ & $65.3 \%$ & $63.8 \%$ & $63.7 \%$ & $66.3 \%$ & $66.3 \%$ \\
\hline \multicolumn{9}{|l|}{ Subsite } \\
\hline Proximal (cardia, C16.0) & $690(36.5 \%)$ & $612(35.2 \%)$ & $764(51.9 \%)$ & $423(42.0 \%)$ & $392(36.4 \%)$ & $401(31.2 \%)$ & $\begin{array}{c}5,326 \\
(30.4 \%)\end{array}$ & $\begin{array}{c}8,608 \\
(33.2 \%)\end{array}$ \\
\hline Distal (non-cardia, C16.1-6) & $633(33.5 \%)$ & $746(42.9 \%)$ & $389(26.4 \%)$ & $339(33.7 \%)$ & $352(32.7 \%)$ & $558(43.4 \%)$ & $\begin{array}{l}6,413 \\
(36.7 \%)\end{array}$ & $\begin{array}{l}9,430 \\
(36.3 \%)\end{array}$ \\
\hline Other/Unspecified (C16.8-9) & $567(30.0 \%)$ & $379(21.8 \%)$ & $319(21.7 \%)$ & $245(24.3 \%)$ & $334(31.0 \%)$ & $328(25.5 \%)$ & $\begin{array}{c}5,754 \\
(32.9 \%)\end{array}$ & $\begin{array}{c}7,926 \\
(30.5 \%)\end{array}$ \\
\hline \multicolumn{9}{|c|}{$\begin{array}{l}\text { Wnited Kingdom registries included: England, Northern Ireland and } \\
\text { Wales }\end{array}$} \\
\hline \multicolumn{9}{|c|}{${ }^{\circ}$ Australia registries included: New South Wales } \\
\hline \multicolumn{9}{|c|}{ I Ireland $(2012-2013)$} \\
\hline \multicolumn{9}{|c|}{$\begin{array}{l}{ }^{\Delta} \text { Includes: data inconsistencies (invalid age, missing/incomplete dates), tumors with non-malignant behavior, tumors with invalid morphological or } \\
\text { topographical codes }\end{array}$} \\
\hline \multicolumn{9}{|c|}{ * Stage error or in situ flag } \\
\hline \multicolumn{9}{|c|}{ َ Gastrointestinal stromal tumour (GIST): ICD-O-3 Morphology code 8936} \\
\hline \multicolumn{9}{|c|}{ § ICD-O-3 Morphology codes 8013, 8041-8045, 8150-8158, 8240-8247, 8249, 8574 and 9091} \\
\hline
\end{tabular}


Table 2. Number of patients with oesophageal and gastric cancer diagnosed during 2012-2014 according to country and stage at diagnosis (TNM and SEER Summary Stage 2000), before and after imputation

\begin{tabular}{|c|c|c|c|c|c|c|c|c|c|c|c|c|c|c|c|c|c|c|}
\hline & \multicolumn{9}{|c|}{ TNM stage } & \multicolumn{9}{|c|}{ Mapped SEER } \\
\hline & \multicolumn{3}{|c|}{ Oesophageal cancer } & \multicolumn{2}{|c|}{$\%$} & \multicolumn{2}{|c|}{ Gastric cancer } & \multicolumn{2}{|c|}{$\%$} & \multicolumn{2}{|c|}{ Oesophageal cancer } & \multirow[b]{2}{*}{$\begin{array}{l}\text { Median age } \\
\text { at diagnosis } \\
\left(\mathrm{P} 25-\mathrm{P} 75^{\ddagger}\right)\end{array}$} & \multicolumn{2}{|r|}{ (1) } & \multicolumn{2}{|c|}{ Gastric cancer } & \multicolumn{2}{|r|}{$\%$} \\
\hline & Stage & Number & $\begin{array}{l}\text { Median age } \\
\text { at diagnosis } \\
\left(\mathrm{P} 25-\mathrm{P} 75^{\ddagger}\right)\end{array}$ & Observed & $\begin{array}{c}\text { After } \\
\text { imputation }\end{array}$ & Number & $\begin{array}{c}\text { Median age } \\
\text { at diagnosis } \\
\left(\mathrm{P} 25-\mathrm{P} 75^{*}\right)\end{array}$ & Observed & $\begin{array}{c}\text { After } \\
\text { imputation }\end{array}$ & Stage & Number & & Observed & $\begin{array}{c}\text { After } \\
\text { imputation }\end{array}$ & Number & $\begin{array}{l}\text { Median age } \\
\text { at diagnosis } \\
\left(\mathrm{P} 25-\mathrm{P} 75^{*}\right)\end{array}$ & Observed & $\begin{array}{c}\text { After } \\
\text { imputation }\end{array}$ \\
\hline \multirow[t]{6}{*}{ Australia } & All patients & & & & & & & & & All patients & 1,365 & $71(63-79)$ & & & 1,890 & $71(61-80)$ & & \\
\hline & Missing & & & & & & & & & Missing & 239 & $73(64-81)$ & 17.5 & & 224 & $74(64-84)$ & 11.9 & \\
\hline & I & & & & & & & & & Localised & 462 & $73(66-83)$ & 41.0 & 42.1 & 542 & $72(62-81)$ & 32.5 & 33.3 \\
\hline & II & & & & & & & & & Regional & 308 & $68(60-77)$ & 27.4 & 26.8 & 480 & $70(60-78)$ & 28.8 & 28.7 \\
\hline & III & & & & & & & & & Distant & 356 & $67(59-76)$ & 31.6 & 31.1 & 644 & $69(59-79)$ & 38.7 & 37.9 \\
\hline & IV & & & & & & & & & & & & & & & & & \\
\hline \multirow[t]{6}{*}{ Canada ${ }^{\dagger}$} & All patients & 1,290 & $67(58-76)$ & & & 1,737 & $71(61-80)$ & & & All patients & 1,290 & $67(58-76)$ & & & 1,737 & $71(61-80)$ & & \\
\hline & Missing & 146 & $72(64-85)$ & 11.3 & & 213 & $81(70-88)$ & 12.3 & & Missing & 83 & $76(66-86)$ & 6.4 & & 148 & $84(74-88)$ & 8.5 & \\
\hline & I & 192 & $70(61-78)$ & 16.8 & 16.9 & 265 & $74(64-82)$ & 17.4 & 18.0 & Localised & 230 & $70(61-78)$ & 19.1 & 19.1 & 308 & $74(64-81)$ & 19.4 & 19.6 \\
\hline & II & 185 & $67(60-75)$ & 16.2 & 16.1 & 207 & $71(63-78)$ & 13.6 & 13.6 & Regional & 362 & $67(59-75)$ & 30.0 & 29.9 & 485 & $69(61-78)$ & 30.5 & 30.3 \\
\hline & III & 278 & $64(58-73)$ & 24.3 & 24.1 & 312 & $67(57-76)$ & 20.5 & 20.2 & Distant & 615 & 64 (57-73) & 51.0 & 51.0 & 796 & $69(59-78)$ & 50.1 & 50.1 \\
\hline & IV & 489 & $65(57-73)$ & 42.7 & 43.0 & 740 & $70(59-78)$ & 48.6 & 48.3 & & & & & & & & & \\
\hline \multirow[t]{6}{*}{ Denmark } & All patients & 1,522 & $69(62-76)$ & & & 1,472 & $70(62-78)$ & & & All patients & 1,522 & $69(62-76)$ & & & 1,472 & $70(62-78)$ & & \\
\hline & Missing & 313 & $74(66-83)$ & 20.6 & & 300 & $76(68-84)$ & 20.4 & & Missing & 256 & $76(67-83)$ & 16.8 & & 246 & $76(68-84)$ & 16.7 & \\
\hline & I & 101 & $67(60-73)$ & 8.4 & 7.9 & 125 & $68(61-76)$ & 10.7 & 10.2 & Localised & 117 & $67(60-74)$ & 9.2 & 9.1 & 134 & $69(62-77)$ & 10.9 & 10.8 \\
\hline & II & 159 & $67(61-74)$ & 13.2 & 13.1 & 174 & $71(63-79)$ & 14.8 & 14.7 & Regional & 509 & $67(60-73)$ & 40.2 & 39.5 & 513 & $69(61-78)$ & 41.8 & 41.5 \\
\hline & III & 483 & $67(60-73)$ & 40.0 & 39.5 & 342 & $68(60-76)$ & 29.2 & 28.9 & Distant & 640 & $68(62-74)$ & 50.6 & 51.4 & 579 & $68(61-76)$ & 47.2 & 47.7 \\
\hline & IV & 466 & $68(62-74)$ & 38.5 & 39.6 & 531 & $68(61-76)$ & 45.3 & 46.1 & & & & & & & & & \\
\hline \multirow[t]{6}{*}{ Ireland" } & All patients & 741 & $70(62-78)$ & & & 1,007 & $72(62-79)$ & & & All patients & 741 & $70(62-78)$ & & & 1,007 & $72(62-79)$ & & \\
\hline & Missing & 255 & $75(66-83)$ & 34.4 & & 312 & $73(63-82)$ & 31.0 & & Missing & 181 & $77(66-84)$ & 24.4 & & 198 & $75(68-83)$ & 19.7 & \\
\hline & I & 34 & $64(57-69)$ & 7.0 & 7.0 & 62 & $73(65-81)$ & 8.9 & 11.2 & Localised & 78 & $67(60-76)$ & 13.9 & 14.0 & 71 & $75(65-82)$ & 8.8 & 10.2 \\
\hline & II & 116 & $69(63-76)$ & 23.9 & 24.2 & 61 & $73(64-77)$ & 8.8 & 10.0 & Regional & 245 & $69(62-76)$ & 43.8 & 45.7 & 302 & $71(61-77)$ & 37.3 & 38.0 \\
\hline & III & 138 & $67(61-75)$ & 28.4 & 29.9 & 143 & $71(63-78)$ & 20.6 & 20.1 & Distant & 237 & $69(60-76)$ & 42.3 & 40.3 & 436 & $70(61-78)$ & 53.9 & 51.8 \\
\hline & IV & 198 & $69(60-76)$ & 40.7 & 38.8 & 429 & $69(61-78)$ & 61.7 & 58.7 & & & & & & & & & \\
\hline \multirow[t]{6}{*}{ New Zealand } & All patients & & & & & & & & & All patients & & & & & 1,078 & $70(59-79)$ & & \\
\hline & Missing & & & & & & & & & Missing & & & & & 498 & $73(63-81)$ & 46.2 & \\
\hline & I & & & & & & & & & Localised & & & & & 83 & $70(48-77)$ & 14.3 & 16.0 \\
\hline & II & & & & & & & & & Regional & & & & & 116 & $70(60-77)$ & 20.0 & 24.8 \\
\hline & III & & & & & & & & & Distant & & & & & 381 & $66(57-77)$ & 65.7 & 59.2 \\
\hline & IV & & & & & & & & & & & & & & & & & \\
\hline \multirow[t]{6}{*}{ Norway } & All patients & & & & & & & & & All patients & 761 & $69(62-78)$ & & & 1,287 & $72(62-80)$ & & \\
\hline & Missing & & & & & & & & & Missing & 227 & $73(66-81)$ & 29.8 & & 274 & $76(66-84)$ & 21.3 & \\
\hline & I & & & & & & & & & Localised & 130 & $70(64-78)$ & 24.3 & 25.0 & 219 & $74(63-82)$ & 21.6 & 21.6 \\
\hline & II & & & & & & & & & Regional & 201 & $67(60-75)$ & 37.6 & 37.4 & 386 & $71(62-79)$ & 38.1 & 38.1 \\
\hline & III & & & & & & & & & Distant & 203 & $67(60-75)$ & 38.0 & 37.7 & 408 & $69(60-78)$ & 40.3 & 40.3 \\
\hline & IV & & & & & & & & & & & & & & & & & \\
\hline $\begin{array}{l}\text { United } \\
\text { Kinodom }\end{array}$ & All patients & 23,244 & $71(63-80)$ & & & 17,493 & $75(66-82)$ & & & All patients & 23,244 & $71(63-80)$ & & & 17,493 & $75(66-82)$ & & \\
\hline & Missing & 6,593 & $77(67-84)$ & 28.4 & & 5,479 & $79(70-85)$ & 31.3 & & Missing & 6,211 & $77(67-84)$ & 26.7 & & 5,255 & $79(70-85)$ & 30.0 & \\
\hline & I & 1,965 & $70(63-78)$ & 11.8 & 11.4 & 1,412 & $75(67-81)$ & 11.8 & 11.1 & Localised & 2,197 & $71(64-78)$ & 12.9 & 12.3 & 1,413 & $75(67-81)$ & 11.5 & 10.9 \\
\hline & II & 2,756 & $71(63-79)$ & 16.6 & 16.3 & 2,216 & $74(66-81)$ & 18.4 & 18.0 & Regional & 7,624 & $70(63-78)$ & 44.8 & 43.5 & 4,973 & $74(65-80)$ & 40.6 & 39.2 \\
\hline & III & 6,186 & $69(62-77)$ & 37.2 & 36.0 & 2,896 & $72(64-79)$ & 24.1 & 22.9 & Distant & 7,212 & $70(62-78)$ & 42.3 & 44.2 & 5,852 & $73(64-80)$ & 47.8 & 49.9 \\
\hline & IV & 5,744 & $70(62-78)$ & 34.5 & 36.4 & 5,490 & $73(64-80)$ & 45.7 & 48.0 & & & & & & & & & \\
\hline
\end{tabular}

${ }^{\dagger}$ Canadian provinces included: Alberta, Manitoba, Newfoundland, Nova Scotia, Prince Edward Island and

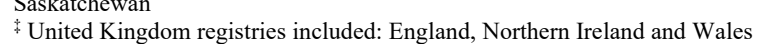

Australia registries included: New South Wales

* 25th-75th percentiles 


\section{FIGURE LEGENDS}

Figure 1. Distribution of (imputed) stage at diagnosis by cancer site, histological subtype, country and staging system, $2012-2014$

$\mathrm{OAC}=$ oesophageal adenocarcinoma $; \mathrm{OSCC}=$ oesophageal squamous cell carcinoma

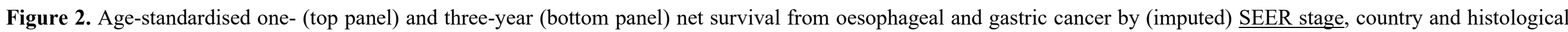
subtype, 2012-2014

$\dagger$ Canadian provinces included: Alberta, Manitoba, Newfoundland, Nova Scotia, Prince Edward Island and Saskatchewan

$\uparrow$ United Kingdom registries included: England, Northern Ireland and Wales

${ }^{\circ}$ Australia registries included: New South Wales

T| Ireland (2012-2013)

$\mathrm{OAC}=$ oesophageal adenocarcinoma $; \mathrm{OSCC}=$ oesophageal squamous cell carcinoma

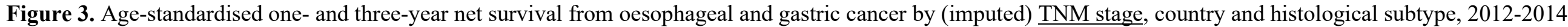

$\uparrow$ Canadian provinces included: Alberta, Manitoba, Newfoundland, Nova Scotia, Prince Edward Island and Saskatchewan

$\$$ United Kingdom registries included: England, Northern Ireland and Wales

qI Ireland (2012-2013)

$\mathrm{OAC}=$ oesophageal adenocarcinoma $; \mathrm{OSCC}=$ oesophageal squamous cell carcinoma 